\title{
Volumetric Changes in the Bony External Auditory Canal in Unilateral Chronic Otitis Media
}

\author{
Jae Hong Park ${ }^{1}$, MinHo Noh ${ }^{1}$, Chi-Kyou Lee ${ }^{1}$, Seung Bum Park ${ }^{1}$, Kye Hoon Park ${ }^{1}$, \\ Jong Kyu $\mathrm{Han}^{2}$, and Hyun Jeong Kim² \\ ${ }^{1}$ Departments of Otorhinolayrngology-Head and Neck Surgery, ${ }^{2}$ Radiology, Soonchunhyang University School of Medicine, \\ Cheonan, Korea
}

Received January 21, 2016

Revised February 19, 2016

Accepted March 8, 2016

Address for correspondence

Chi-Kyou Lee, MD, PhD

Department of Otorhinolarygology-

Head \& Neck Surgery,

Soonchunhyang University

School of Medicine,

31 Suncheonhyang 6-gil,

Dongnam-gu, Cheonan 31151, Korea

Tel +82-41-570-2353

Fax +82-41-579-9022

E-mail drqlee@hanmail.net
Background and Objectives: Pneumatization of air cells in the mastoid bone is decreased in chronic otitis media (COM). A decrease in the size of the external auditory canal (EAC) is also found frequently in patients with $\mathrm{COM}$, but this has been little studied. We compared the size of affected bony EACs and the contralateral side in patients with single-side COM using high-resolution computed tomography. Subjects and Methods: In total, 99 patients with single-side COM were included. Four indicators related to the size of the bony EAC and IAC were measured using high-resolution computed tomography: the axial and coronal lengths of the tympanic membrane, the length of the isthmus, and the area of the bony ear canal. We also compared both internal auditory canals as negative controls. These assessments were made by radiologists who were blinded to the objective of this study. Results: In patients with single-side COM, the axial length of the tympanic membrane was significantly shorter than normal, and the volume of the EAC was also significantly smaller. The length of the isthmus of the EAC was shorter on the affected side, but the difference was not significant. The IAC volume showed no difference between the two sides. Conclusions: COM affects general temporal bony development, including the bony EAC and mastoid bone. Therefore, whether to correct this should be considered when preparing for COM surgery.

J Audiol Otol 2016;20(1):41-46

KEY WORDS: External auditory canal · Computed tomography · Otitis media.

\section{Introduction}

A decreased number of air cells in the mastoid is common in chronic otitis media (COM). There are two theories. The environmental theory suggests that frequent inflammatory changes in the upper respiratory tract, Eustachian tube, and middle ear cavity hamper the development of the air cells of the mastoid or calcify the existing air cells. The hereditary theory suggests that congenitally poor air cells in the mastoid do not provide a good air buffer for the middle ear cavity, leading to the development of COM $[1,2]$.

It is not unusual that the space in the external auditory ca-

This is an Open Access article distributed under the terms of the Creative Commons Attribution Non-Commercial License (http://creativecommons. org/licenses/by-nc/3.0/) which permits unrestricted non-commercial use, distribution, and reproduction in any medium, provided the original work is properly cited. nal (EAC) is smaller in COM patients than in patients who have only sensorineural hearing loss, tinnitus, dizziness, or trauma. This difference may be explained by the mastoid air cell theories; however, there is not enough evidence to confirm this, and there are also insufficient objective data to analyze the bony EAC.

High-resolution computed tomography (HRCT) is an effective tool to examine anatomical relationships between the temporal bones of the middle and inner ear, and has been used to study the pneumatization of the mastoid air cell system. With appropriate CT images, the three-dimensional (3D) structure of the ear can be analyzed. In this study, we used HRCT to compare the volumes of the bony EAC in patients with unilateral COM and assessed the reasons for any difference. 


\section{Subjects and Methods}

This study included 99 patients who were treated for unilateral COM and had HRCT in our hospital between 2010 and 2015. There were 53 men and 46 women, ranging in age from 15 to 85 years (average, 46.3 years). We excluded patients with cholesteatoma, congenital anomalies, head trauma, or a history of meningitis. We classified the ears as being on the healthy side (EAC_N) or the diseased side (EAC_D).

Axial HRCT images were taken parallel to Reid's base line at $1.24 \mathrm{~mm}$ using a Light Speed VCT (GE Medical Systems, Milwaukee, WI, USA); coronal images were taken vertical to this line in the same space. All images were analyzed by two radiologists, who were not informed about the aims of this study, and their data were averaged.

We defined the following factors:

1) The length of the axial ear drum: the shortest length crossing the umbo between the anterior and posterior bony annuli (Fig. 1A, axial image).

2) The length of the coronal ear drum: the shortest length passing the handle of the malleus between the superior and inferior bony annuli (Fig. 1B, coronal image).

3) The axial and coronal isthmus of the bony EAC: the shortest length from the anterior to the posterior bony EAC wall in axial images and from the superior to the inferior bony EAC wall in coronal images (Fig. 2).

4) The volumes of the EAC and the internal acoustic meatus (IAC): the two volumes were calculated automatically using the bundled software (GE Medical Systems), by outlining the bony margin of the two spaces (performed by the radiologist; Fig. 3, 4).

\section{Statistical analysis}

To compare the data, we used SPSS for Windows software (ver. 20.0; IBM, Armonk, NY, USA). We deemed $p<0.05$ to indicate statistical significance. The Kolmogorov-Smirnov test was used to test whether our data were normally distributed. In cases of normally distributed data, we used the paired t-test; if the date were not normal, we used the Wilcoxon signed-rank test. To analyze the correlation of the volume of the bony EAC with the others, we used a multiple linear regression model.
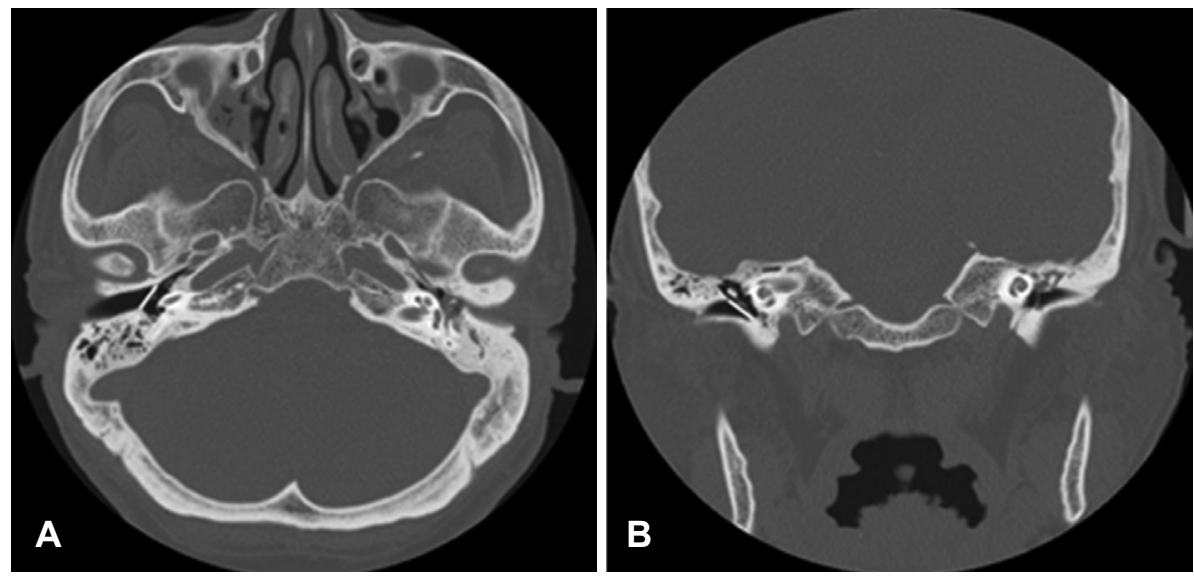

Fig. 1. Axial (A) and coronal (B) images show the length (white line) of the tympanic membrane. The axial length was measured by a line between the two bony annuli crossing the umbo. The coronal length was measured by a line (white line) between the bony annuli passing the handle of the malleus.

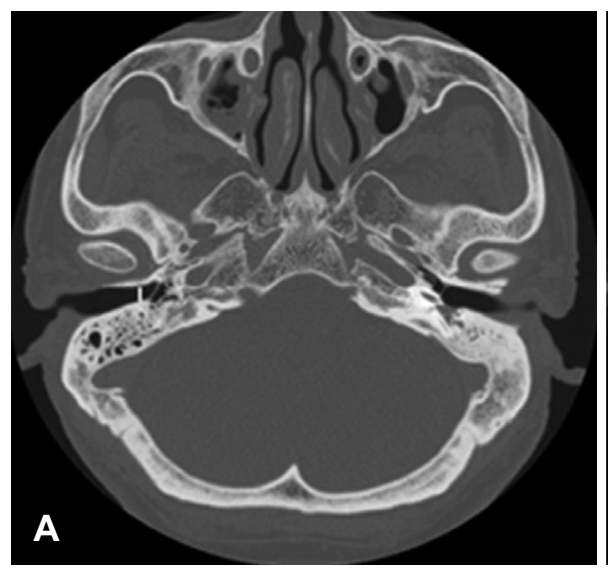

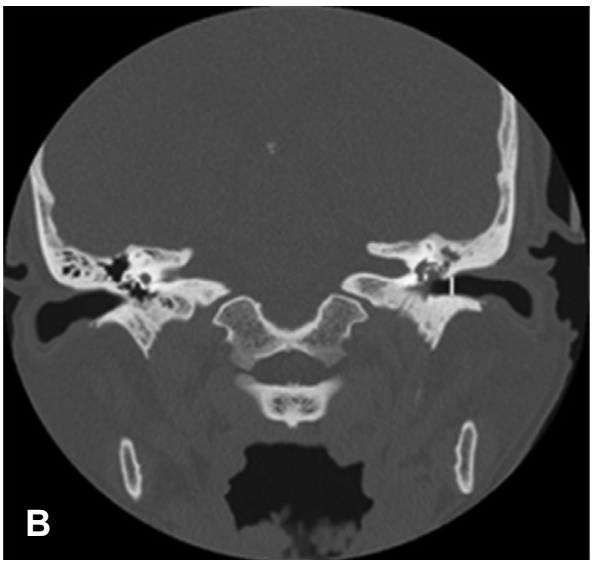

Fig. 2. Axial (A) and coronal (B) images show the length (white line) of the isthmus, the narrowest portion of the external auditory canal. 
Fig. 3. Axial image shows the area of the external auditory canal (EAC) bony portion. The white line shows the contour of the bony EAC, drawn manually. The right picture illustrates reconstruction of the virtual bony $\mathrm{EAC}$, and the volume of the bony EAC was calculated automatically.

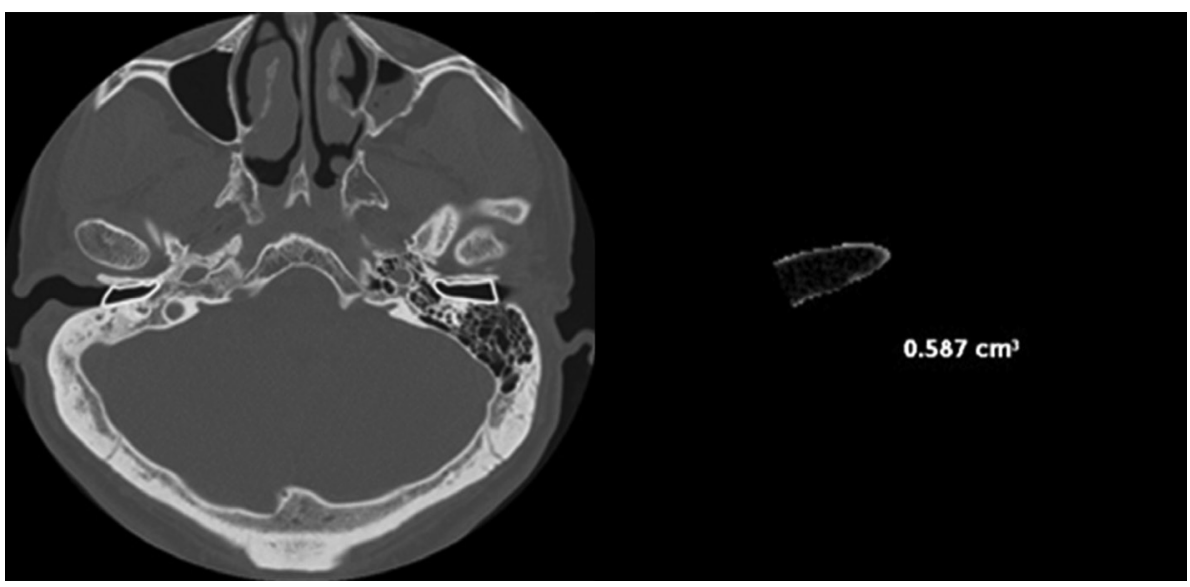

Fig. 4. The contour of the internal acoustic meatus (IAC) was drawn manually, and the volume of the IAC was calculated in the same way.

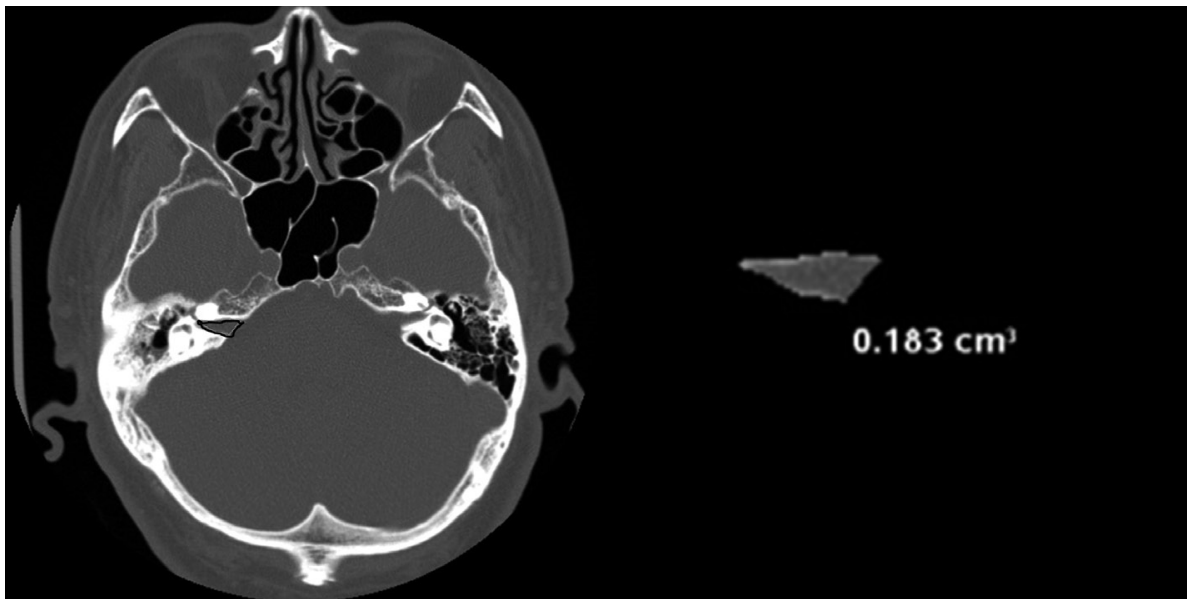

\section{Results}

Regarding COM, there were 55 right-side cases and 54 leftside cases. There were no significant differences in laterality or gender. In the EAC_D group, the pure tone average (PTA) was $19.17 \mathrm{~dB}$ for bone conduction and $42.83 \mathrm{~dB}$ for air conduction. In the EAC_N group, PTA was $15.75 \mathrm{~dB}$ for both air and bone conduction. There was no significant difference in bone conduction PTA between the two groups. PTA was calculated for averages of 500, 1,000, 2,000, and 3,000 Hz (Table 1). When we measured the length of the ear drum, the axial lengths were $8.38 \mathrm{~mm}(\mathrm{SEM}=0.40)($ EAC_D) and 8.56 $\mathrm{mm}(\mathrm{SEM}=0.40)(\mathrm{EAC} \mathrm{N})$, and the coronal lengths were 8.34 $\mathrm{mm}(\mathrm{SEM}=0.48)\left(\mathrm{EAC} \_\mathrm{D}\right)$ and $8.55 \mathrm{~mm}(\mathrm{SEM}=0.44)(\mathrm{EAC}$ $\mathrm{N})$. Both lengths were longer on the normal side but only axial length differed significantly $(p=0.021)$ (Fig. 5). The axial lengths of the isthmus were $5.46 \mathrm{~mm}(\mathrm{SEM}=0.82)(\mathrm{EAC} D)$ and $5.58 \mathrm{~mm}(\mathrm{SEM}=0.83)\left(\mathrm{EAC} \_\mathrm{N}\right)$, and the coronal lengths of the isthmus were $5.45 \mathrm{~mm}(\mathrm{SEM}=0.75)(\mathrm{EAC} \mathrm{D})$ and 5.56 $\mathrm{mm}(\mathrm{SEM}=0.73)(\mathrm{EAC}$ N) (Fig. 6); the differences were not significant. The volumes of the EAC were $0.46 \mathrm{~cm}^{3}(\mathrm{SEM}=$
Table 1. Demographic characteristics of the patients

\begin{tabular}{lc}
\hline Demographic characteristic & \\
\hline Age (years) & $46.3 \pm 7.1(17-85)$ \\
Gender (male/female) & $53 / 46$ \\
Side of chronic otitis media (right/left) & $55 / 54$ \\
Pure tone audiometry & \\
Disease ear & \\
$\quad$ Air conduction (dB HL) & 42.83 \\
$\quad$ Bone conduction $(\mathrm{dB} \mathrm{HL})$ & 19.17 \\
$\quad$ Air-bone gap (dB HL) & 23.67 \\
Healthy ear & \\
$\quad$ Air conduction (dB HL) & 15.75 \\
Bone conduction $(\mathrm{dB} \mathrm{HL})$ & 15.75 \\
Air-bone gap (dB HL) & 0 \\
\hline
\end{tabular}

0.07) $\left(\right.$ EAC_D) and $0.56(\mathrm{SEM}=0.09) \mathrm{cm}^{3}\left(\mathrm{EAC} \_\mathrm{N}\right)$. There was a significant difference between the two volumes $(p=$ $0.000)$ (Fig. 7). The volumes of the IAC were $0.18 \mathrm{~cm}^{3}(\mathrm{SEM}=$ $0.03)\left(\right.$ EAC_D) and $0.17 \mathrm{~cm}^{3}(\mathrm{SEM}=0.03)($ EAC_N) (Fig. 8). There was no significant difference between the two volumes.

We used a multiple linear regression model to assess the 
relationship between the volume of the EAC and the others. There was no relationship on the healthy side, but there was a significant relationship between the volume of the EAC and the coronal length of the isthmus in the EAC_D group. After backward selection, the axial length of the ear drum was also significantly related to the volume of the EAC_D. With a decrease of $1 \mathrm{~mm}$ in the axial length of the eardrum, the volume of the EAC_D decreased by $0.93 \mathrm{~mm}^{3}(95 \% \mathrm{CI}=0.87-1.00$ $\mathrm{mm}^{3}, p=0.047$ ). Also, with a decrease of $1 \mathrm{~mm}$ in the coronal length of the isthmus, the volume of the EAC_D decreased by $0.92 \mathrm{~mm}^{3}\left(95 \% \mathrm{CI}=0.86-0.99 \mathrm{~mm}^{3}, p=0.032\right)$ (Table 2$)$.

\section{Discussion}

The number of mastoid air cells is often relatively low in patients with COM. There have been many reports about the relationship between the pneumatization of mastoid air cells

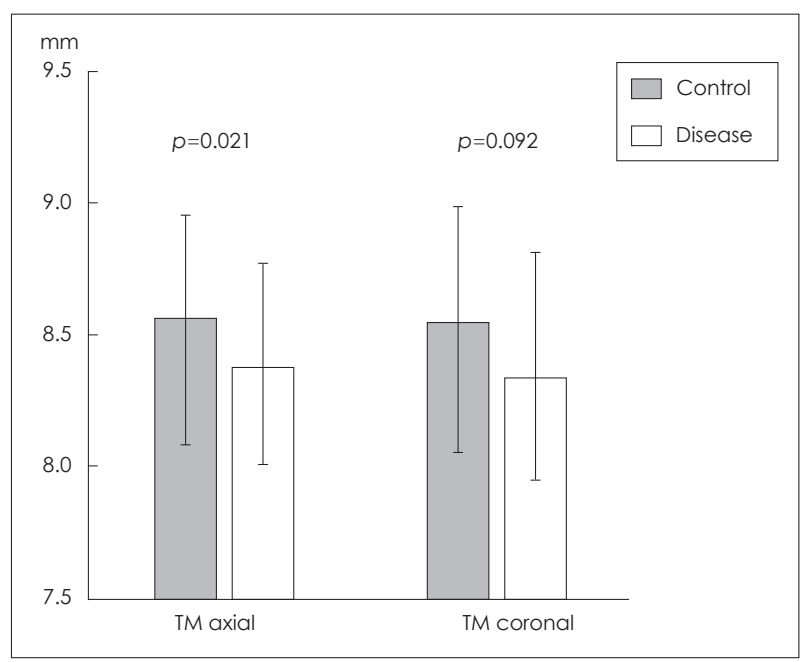

Fig. 5. Axial and coronal lengths of the tympanic membrane.TM: tympanic membrane.

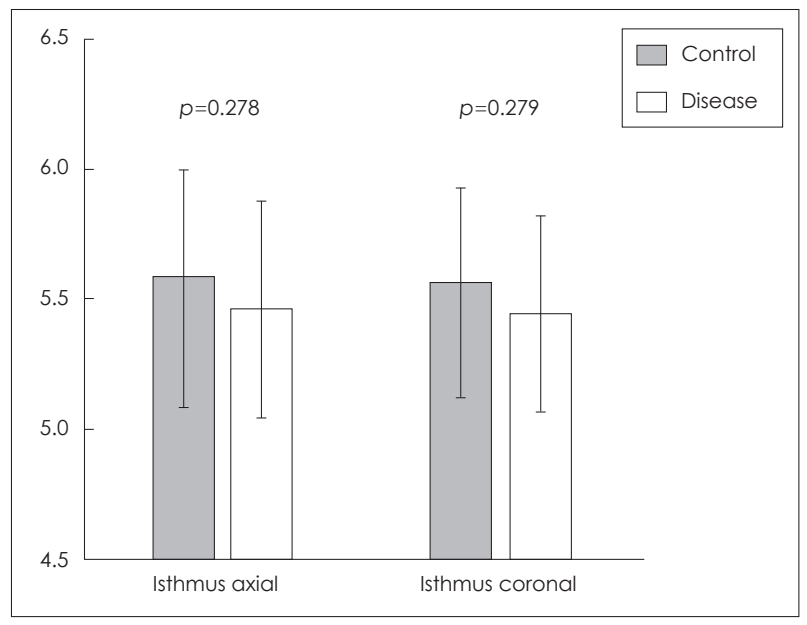

Fig. 6. Axial and coronal lengths of the isthmus. and inflammation in the middle ear: the greater the increase in COM, the greater the decrease in pneumatization [3]. There are two explanations for this phenomenon: the environmen-

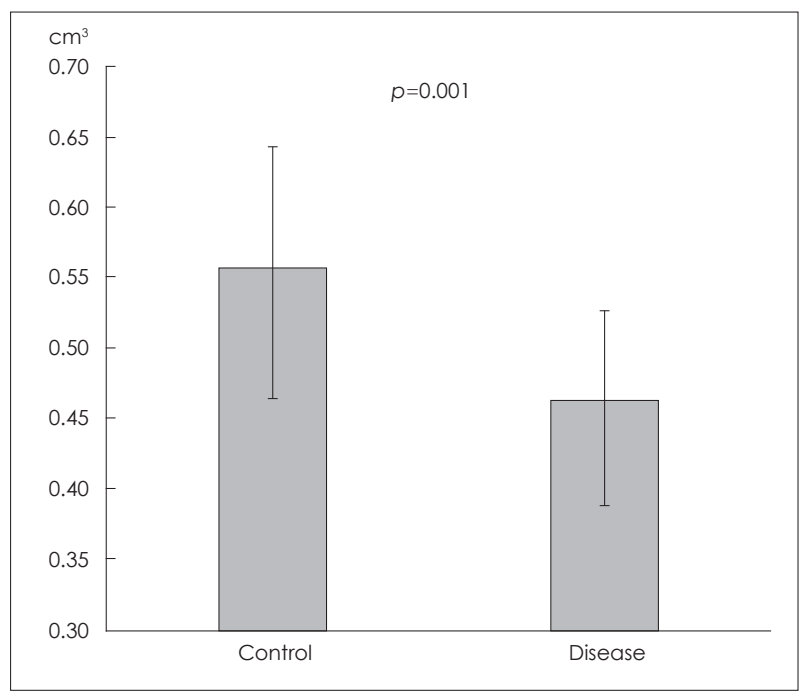

Fig. 7. Volume of the bony external auditory canal.

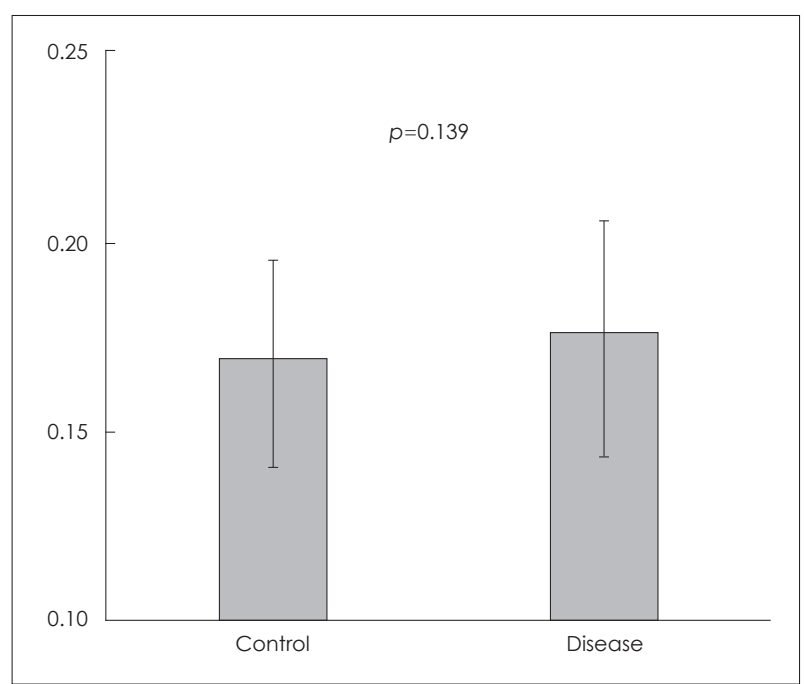

Fig. 8. Volume of the internal auditory canal.

Table 2. Multiple linear regression model for prediction of external auditory canal volume $\left(\mathrm{mm}^{3}\right)$

\begin{tabular}{llll}
\hline & RC (beta) & $95 \% \mathrm{Cl}$ & p-value \\
\hline Disease side & & & \\
TM axial distance $(\mathrm{mm})$ & 0.92 & $0.83-1.01$ & 0.069 \\
TM coronal distance $(\mathrm{mm})$ & 1.03 & $0.95-1.11$ & 0.526 \\
Isthmus axial distance $(\mathrm{mm})$ & 1.1 & $0.96-1.26$ & 0.169 \\
Isthmus coronal distance $(\mathrm{mm})$ & 0.84 & $0.72-0.98$ & $0.025^{*}$ \\
After backward selection & & & \\
TM axial distance $(\mathrm{mm})$ & 0.93 & $0.87-1.00$ & $0.047^{*}$ \\
Isthmus coronal distance $(\mathrm{mm})$ & 0.92 & $0.86-0.99$ & $0.032^{*}$ \\
\hline
\end{tabular}

*significant relationship. TM: tympanic membrane, RC: regression coefficient, $\mathrm{Cl}$ : confidence interval 
tal theory and the hereditary theory. According to the hereditary theory, congenitally small mastoid air cells result in more frequent otitis media. Shatz and Sadé [1] presented evidence such as a consistent length from the cortical mastoid bone to the sigmoid sinus. However, Tos and Stangerup [2] insisted on the environmental theory, according to which chronic recurrent otitis media causes chronic subperiosteal inflammation, thereby interfering with the development of mastoid air cells [3-5].

Although the EAC is composed almost entirely of cartilaginous parts in neonates, the bony EAC grows rapidly and laterally throughout childhood. The total length of the EAC is about $25 \mathrm{~mm}$; the bony EAC accounts for about two-thirds of this length, i.e., almost $15 \mathrm{~mm}[6,7]$.

In this study, we compared intrapersonal differences in both bony EACs in adults, to minimize variables affecting the outcome. Normal EAC (EAC_N) denotes a normal eardrum without conductive hearing loss, whereas diseased EAC (EAC_ D) denotes a perforated eardrum with conductive hearing loss. We excluded congenital ear anomalies to set aside genetic effects. We also excluded cholesteatoma and head trauma cases because cholesteatoma can cause deformity of the EAC.

The axial length of the eardrum was significantly shorter in the EAC_D group, but not the coronal length (Fig. 5). The length of the isthmus did not differ between the two groups. Our data suggest that anteroposterior growth of the eardrum is more important than superoinferior growth after birth. We expected that isthmic length would also be shorter in the EAC_D group than in the EAC_N, group, but this was not the case. Koo, et al. [8] reported an axial isthmic length of 5.5 $\pm 1.6 \mathrm{~mm}$ and a coronal isthmic length of $7.2 \pm 1.0 \mathrm{~mm}$. Their results differ from ours, probably because there is no accepted point at which to measure isthmic length. We suggest that measuring isthmic length on two-dimensional (2D) images is not suitable as an objective parameter to reflect the state of the EAC.

Previous studies reported analyses of anatomical variations in temporal bone using CT images: sigmoid sinus, facial nerve and mastoid pneumatization [9]. As technology has progressed, many CT vendors have supplied software for simulating 3D structures from 2D images. 3D images are more consistent for analyzing structures. In the comparison of both EAC volumes of unilateral COM patients in our study, the differences were significantly greater versus the normal side (Fig. 7). This could indicate that COM hampers growth of the bony EAC or that a congenitally small EAC causes COM. To assess these possibilities, we compared the IAC volumes. If the difference arises from congenital causes, the IAC might also show the same difference. However, there was no difference between the IAC volumes (Fig. 8). We excluded patients who had a history of meningitis, because this can cause narrowing of the IAC. Based on these findings, we suggest that environmental factors are more influential than hereditary ones. Also, the bony EAC develops mostly after birth. There are two mechanisms by which the bony EAC may narrow: impeded temporal bone growth; and promotion of new bone formation (thereby narrowing the lumen of the bony EAC).

Measuring the volume of the bony EAC is not trivial. Thus, we also analyzed the relationship between bony EAC volume and the other factors. Two factors correlated with the volume: the axial length of the eardrum and coronal isthmic length (Table 2). As mentioned above, the axial eardrum length was more consistent. Thus, we recommend using this parameter to reflect the general developmental state of the temporal bone. We also wanted to analyze the relationship between the duration of otitis media and stenosis of the bony EAC, to assess whether longer exposure to otitis media was associated with more narrowing of the bony EAC. However, this is not easy because recollection regarding disease onset is inaccurate in many patients. Therefore, to determine this relationship, we may have to plan a prospective study to observe children with otitis media over a long period.

In conclusion, the growth of bony EAC can be affected by $\mathrm{COM}$ as mastoid pneumatization. If so, we need to actively treat children's otitis media to prevent these sequelae. We also have to consider this when operating on patients with COM.

\section{Conflicts of interest}

The authors have no financial conflicts of interest.

\section{REFERENCES}

1) Shatz A, Sadé J. Correlation between mastoid pneumatization and position of the lateral sinus. Ann Otol Rhinol Laryngol 1990;99(2 Pt 1):142-5.

2) Tos M, Stangerup SE. The causes of asymmetry of the mastoid air cell system. Acta Otolaryngol 1985;99:564-70.

3) Aoki K, Esaki S, Honda Y, Tos M. Effect of middle ear infection on pneumatization and growth of the mastoid process. An experimental study in pigs. Acta Otolaryngol 1990;110:399-409.

4) Ichijo H, Hosokawa M, Shinkawa $H$. The relationship between mastoid pneumatization and the position of the sigmoid sinus. Eur Arch Otorhinolaryngol 1996;253:421-4.

5) Turgut S, Tos M. Correlation between temporal bone pneumatization, location of lateral sinus and length of the mastoid process. $\mathrm{J}$ Laryngol Otol 1992;106:485-9.

6) Dahm MC, Shepherd RK, Clark GM. The postnatal growth of the temporal bone and its implications for cochlear implantation in children. Acta Otolaryngol Suppl 1993;505:1-39.

7) Virapongse C, Sarwar M, Sasaki C, Kier EL. High resolution computed tomography of the osseous external auditory canal: 1 . Normal anatomy. J Comput Assist Tomogr 1983;7:486-92. 
8) Koo GJ, Goh EK, Yun JH, Lee CH, Koo SK, Lee SH, et al. Computed tomographic measurements of the external auditory canal and the temporal bone. Korean J Otolaryngol-Head Neck Surg 2002;45: $238-44$.
9) Lee SH, Seo IS, Kim KT, Jang YH, Kim KR, Park CW. Variations of surgical anatomy in the unilateral sclerotic temporal bone. Korean J Otolaryngol-Head Neck Surg 2003;46:928-34. 